\title{
Phylogenetic and Functional Traits Verify the Combined Effect of Deterministic and Stochastic Processes in the Community Assembly of Temperate Forests along an Elevational Gradient
}

\author{
Wensong Zhou ${ }^{1} \mathbb{D}$, Yuxin Zhang ${ }^{1, *}$, Shuang Zhang ${ }^{1}$, Basil N. Yakimov ${ }^{2}$ and Keming Ma ${ }^{1,3}$ \\ 1 State Key Laboratory of Urban and Regional Ecology, Research Center for Eco-Environmental Sciences, \\ Chinese Academy of Sciences, Beijing 100085, China; zwszhouwensong@163.com (W.Z.); \\ shuangzhang@rcees.ac.cn (S.Z.); mkm@rcees.ac.cn (K.M.) \\ 2 Department of Ecology, Lobachevsky State University of Nizhny Novgorod, pr. Gagarina 23, \\ 603950 Nizhny Novgorod, Russia; damselfly@yandex.ru \\ 3 University of Chinese Academy of Sciences, Beijing 100049, China \\ * Correspondence: yxzhang@rcees.ac.cn
}

\section{check for} updates

Citation: Zhou, W.; Zhang, Y.; Zhang, S.; Yakimov, B.N.; Ma, K. Phylogenetic and Functional Traits Verify the Combined Effect of Deterministic and Stochastic Processes in the Community Assembly of Temperate Forests along an Elevational Gradient. Forests 2021, 12, 591. https://doi.org/10.3390/ f12050591

Academic Editor: Andrea Coppi

Received: 24 March 2021

Accepted: 6 May 2021

Published: 8 May 2021

Publisher's Note: MDPI stays neutral with regard to jurisdictional claims in published maps and institutional affiliations.

Copyright: (C) 2021 by the authors Licensee MDPI, Basel, Switzerland. This article is an open access article distributed under the terms and conditions of the Creative Commons Attribution (CC BY) license (https:// creativecommons.org/licenses/by/ $4.0 /)$.

\begin{abstract}
Explaining community assembly mechanisms along elevational gradients dominated by deterministic processes or stochastic processes is a pressing challenge. Many studies suggest that phylogenetic and functional diversity are significant indicators of the process. In this study, we analyzed the structure and beta diversity of phylogenetic and functional traits along an elevational gradient and discussed the effects of environmental and spatial factors. We found that the phylogenetic and functional traits showed inconsistent changes, and their variations were closely related to the abiotic environment. The results suggested that the community assembly of woody plants was obviously affected by the combined effect of deterministic processes and the stochastic hypothesis (primarily by the latter). Phylogenetic and functional traits had a certain relationship but changed according to different rules. These results enhance our understanding of the assembly mechanism of forest communities by considering both phylogenetic and functional traits.
\end{abstract}

Keywords: phylogeny; functional trait; elevational gradient; community assembly; woody plant

\section{Introduction}

The assembly mechanism of plant communities has always been an important topic in ecological research [1]. Understanding what drives the variation in a community can provide insights into the mechanisms of community assembly [2]. There are two main hypotheses used to explain the mechanism of community assembly: the deterministic hypothesis based on niche theory and the stochastic hypothesis based on neutral theory. The deterministic hypothesis states that the restriction of environmental conditions and the interaction between organisms will screen the species entering the community and result in a stable community. The main drivers of this hypothesis are habitat filtering and competitive exclusion [3]. In contrast, the stochastic hypothesis states that the probability of entering a community is equal among all species; niche differences and competition do not affect species coexistence, community assembly is a random ecological drift process of equivalent individuals, and the main drivers are dispersion limitation and random effect $[4,5]$. Both hypotheses could solve some problems; however, some existing phenomena remain unexplained [6]. Therefore, it is generally believed that the two hypotheses should be incorporated to explain the mechanism of community assembly $[7,8]$. Some studies found that both hypotheses reflected different aspects of community construction, and the more important hypothesis may depend on the current environmental conditions [9]. For example, the deterministic hypothesis may play a greater role in adverse environments [10]. 
Due to the prominent impact of temperature, both elevational gradients and latitudinal gradients are important factors that affect species assembly in communities, and these gradients could affect some temperature-related variables, such as species distribution, diversity, phenotypes, and growing season duration [11,12]. Ecologists have found that the change in community composition along an elevational gradient could better verify the ecological hypothesis of community construction than the change along a latitudinal gradient $[13,14]$. There have been many studies on the relationships of community phylogeny from the perspective of elevational gradients, which include research studies in botany [15-17], zoology [18-20], and microbiology [21,22]. Current research has shown that the process of community assembly is the result of a combination of deterministic and stochastic processes [23]: the transformation mechanism of phylogeny and functional traits is related to the elevational gradient [24] and phylogenetic clustering becomes more obvious with increasing elevation [25]. However, the phylogenetic structure of soil bacteria and plants presents an opposite pattern along the elevational gradient when plants and microorganisms are compared to each other [26].

Furthermore, a major goal of trait-based ecology is to use simple measurements of traits to create and inform predictive models of community assembly [27]. Variations in plant functional traits along elevational gradients, whether caused by phenotypic plasticity or genetic divergence, may influence how communities and ecosystems respond to global change [12]. For example, to cope with abiotic gradients across elevations, plants in disparate taxa have evolved parallel morphological and physiological traits at high and low elevations [28]. Furthermore, as a result of the diversity of functional traits in a limited environment, which could increase the complementarity of the niche through the effective utilization of resources by different species [29], the relationship between functional trait diversity and ecosystem function was closer than that of species diversity [30]. Another study indicated that easily measured traits can provide ecologically relevant information on the life history strategies of plants and their contributions to ecosystem functioning [31]. Plants are sensitive to climate change, and their functional traits influence their abilities to live in specific habitats. A study showed that the change trends of different traits along an elevation gradient were different, which revealed that trait variation occurred in response to environmental drivers and change [32].

Recently, phylogenetic and functional trait studies have improved our understanding of the ecological and evolutionary mechanisms of community assembly [33,34]. Phylogenetic diversity reflects the biogeographical history and evolutionary process of the community, while functional diversity provides a way to infer current ecological process information by morphological, physiological, and ecological characteristics [35]. However, phylogeny and functional traits do not necessarily present similar information and patterns [36,37], and the similarity is decided by the intensity of the phylogenetic signal of functional traits, which in turn depends on the ecological processes of species diversity and niche evolution [38,39]. Therefore, the joint analysis of phylogeny and functional traits could reveal the impact of community evolution history (phylogenetic diversity) and specific phenotypic traits (functional diversity) simultaneously on the current community ecological process $[40,41]$. Phylogenetic diversity and functional trait diversity have contributed to revealing the ecological processes responsible for evolution and functional assembly [42]. A study confirmed that the diversity of species functional traits at different sites is closely related to phylogenetic variation [43]. Another study confirmed that the phylogenetic diversity-area relationship (PDAR) and functional diversity-area relationship (FDAR) were highly correlated with the species-area relationship (SAR), which suggested that the species interactions were often influenced by phylogenetic and functional similarities [44].

Woody plants are the main component of forest communities and represent most of the biomass and productivity. As the most important link in the construction of forest communities in mountainous areas, studying the phylogeny and functional traits of woody plants is advantageous for understanding the discrepancies in community assem- 
bly mechanisms along elevational gradients. To date, many studies have shown that the deterministic process dominates community assembly along elevational gradients, and the change patterns of phylogenetic and functional traits are also different $[23,45,46]$. In this study, based on elevational gradient transect data and other scholars' conclusions, we propose theoretical expectations: the changes in phylogenetic and functional traits along the elevational gradient are consistent in mountain forest communities, the changes in abiotic environmental gradients have certain effects on the beta diversity of phylogenetic and functional traits, and the combined effect of deterministic processes and stochastic hypotheses guide community assembly.

To test these hypotheses, we analyzed the structure and beta diversity of phylogenetic and functional traits, tested the phylogenetic signals of functional traits, and discussed the interpretive ability of environmental factors to explain the phylogenetic and functional traits.

\section{Materials and Methods}

\subsection{Study Site}

Donglingshan Mountain is an extension of the Xiaowutaishan Mountains and belongs to the broader Taihangshan Mountains, and is located $100 \mathrm{~km}$ northwest of Beijing city, China. The study area, the Beijing Forest Ecosystem Research Station of the Chinese Academy of Sciences, is located at $40^{\circ} 00^{\prime}-40^{\circ} 03^{\prime} \mathrm{N}$ and $115^{\circ} 26^{\prime}-115^{\circ} 30^{\prime} \mathrm{E}$. The soil type of the area is brown soil classified as Eutric cambisol. The area has a typical warm temperate continental monsoon climate with an average annual precipitation of 500-650 $\mathrm{mm}$. The mean annual temperature is $5-10^{\circ} \mathrm{C}$. The elevation of most of the area is more than $1000 \mathrm{~m}$ above sea level, and the elevation of the highest peak is $2303 \mathrm{~m}$.

The zonal vegetation of the Donglingshan Mountain region is a highly heterogeneous warm temperate-zone deciduous broad-leaved forest, including mainly oaks (Quercus L. spp.), mixed species (e.g., Tilia L. spp., Ulmus L. spp., Acer L. spp., Juglans mandshurica Maxim., and Fraxinus rhynchophylla Hance), birches (Betula L. spp.), and poplar (Populus davidiana Dode). There are also some conifers and shrubs (e.g., Prunus L. spp. and Vitex negundo var. heterophylla (Franch.) Rehd.).

\subsection{Data Collection}

We chose the well-developed Quercus wutaishanica Blume. forest on the west slope, and ten transects were established according to the elevational gradient. Several $10 \mathrm{~m} \times 10 \mathrm{~m}$ quadrats were separated along each transect, with a total of 119 quadrats (Appendix A). The coordinates, elevation, slope exposition, and slope were recorded, and standard plant community surveys were carried out. We investigated the species identity, diameter at breast height $(\mathrm{DBH})$, and height of all tree species, divided the quadrat into four $5 \mathrm{~m} \times 5 \mathrm{~m}$ quadrats, and investigated the species identity, quantity, height, and coverage of all shrub species. Additionally, soil samples were collected by a $5 \mathrm{~cm}$ diameter earth drill, and five sites were selected randomly from each $10 \mathrm{~m} \times 10 \mathrm{~m}$ quadrat to collect the surface soil $(0-10 \mathrm{~cm})$; these were mixed into one composite sample and used for soil physiochemical property analysis after passing through a $2 \mathrm{~mm}$ diameter soil sieve and being placed indoors to naturally air dry [47]. Soil temperature and moisture were measured by a soil moisture tester (TDR 350, Spectrum); soil pH was measured by a pH meter (PB-10, Sartorius); soil total carbon, organic carbon, and total nitrogen content were determined by an element analyzer (Vario EL III, Elementar); and soil total phosphorus content was determined by a continuous flow analyzer (SKALAR SAN++, SKALAR) [48].

Leaves of all mature woody plants were collected in August 2019. We collected leaves from each species. At least five individuals in each $10 \mathrm{~m} \times 10 \mathrm{~m}$ quadrat and 10-20 intact, mature, and healthy leaves were collected on the dayside near the canopy for each individual, and the functional properties were determined after returning to the laboratory. We selected 13 traits that reflect the characteristics of plants: leaf area (LA), specific leaf area (SLA), leaf length (LL), leaf width (LW), leaf thickness (LT), and leaf 
dry matter content (LDMC) were selected for the chemical properties of leaves; leaf total carbon content (LTC), leaf total nitrogen content (LTN), leaf total phosphorus content (LTP), leaf total potassium content (LTK), the ratio of carbon to nitrogen of a leaf $(\mathrm{L} \mathrm{C} / \mathrm{N})$, and the ratio of nitrogen to phosphorus of a leaf $(\mathrm{L} \mathrm{N} / \mathrm{P})$ were selected for the physical properties of leaves; finally, the relative content of chlorophyll (RCC) was selected for the photosynthetic capacity of a leaf (Appendix B). LL, LW, and LT were measured by a Vernier caliper (DL 3941, Deli, Ningbo, China); LA was collected by a CanoScan LiDE 220 scanner (Canon, Tokyo, Japan) and measured by ImageJ 1.49v software (Wayne Rasband, National Institutes of Health, Stapleton, NY, USA); the relative chlorophyll content was measured by a SPAD-502plus chlorophyll meter (KONICA MINOLTA, Tokyo, Japan); leaf fresh weight was measured by an electronic balance; leaf dry weight was also measured by an electronic balance after drying in an oven at $80^{\circ} \mathrm{C}$ for $48 \mathrm{~h}$; and LTC, LTN, LTP, and LTK were measured by a J200 LIBS laser spectral element analyzer (ASI, Sacramento, CA, USA).

\subsection{Phylogenetic Tree}

According to the investigation, 30 species of woody plants were recorded in 10 transects, and there were 15 tree species, such as Quercus wutaishanica Blume, Fraxinus chinensis Roxb., and Acer mono Maxim. The shrub species included Spiraea trilobata L., Abelia biflora Turcz., Rhododendron micranthum Turcz., and 12 other species (Appendix C). We counted the family and genus information of all woody plants, and a phylogenetic tree of woody plants was reconstructed by using phylomatic (V3) software based on the Zanne 2014 phylogenetic hypothesis (Appendix E) [49]. Quercus wutaishanica Blume and Spiraea trilobata L. were the absolute dominant species in the tree layer and shrub layer, respectively, and the two populations had high abundances and were present in each transect.

\subsection{Data Analysis}

To test the correlation between functional traits and species evolutionary history, phylogenetic signals of functional traits were calculated by Blomberg's K method [50]. If the $P$ value was not significant, there was no phylogenetic signal. Significant values lower than 0.8 indicate a low /weak phylogenetic signal, values within $0.8-1.1$ indicate the trait follows a Brownian motion, and values $>1.1$ indicate a strong phylogenetic signal. Phylogenetic and functional trait structures were calculated by the mean phylogenetic distance between species (MPD) and the mean nearest taxon distance (MNTD). Phylogenetic and functional trait beta diversities were calculated by the mean pairwise distance (Dpw) and the nearest neighbor distance (Dnn), respectively. We transformed the empirical value to a standardized effect size (SES value) by subtracting the mean of the null distribution and dividing by the standard deviation of the null distribution, and species richness was considered in the calculation process [51,52]. The null model "richness" was used, and the analysis was completed in R 4.0.3 [53]. Structure overdispersion occurred if the SES value $>0$, clustering occurred if the SES value $<0$, the structure was completely random if the SES value $=0$, and the SES value was significant when it was greater than 1.96 or less than -1.96 .

Environmental factors and spatial factors were investigated as variables for redundancy analysis (RDA) of the structure of phylogenetic and functional traits. Elevation, slope exposition, slope, soil temperature, soil moisture content, soil $\mathrm{pH}$, soil total carbon content, soil total nitrogen content, soil total phosphorus content, soil organic carbon content, ratio of soil carbon to nitrogen, and the ratio of soil nitrogen to phosphorus were chosen as environmental factors. Six principal coordinates of neighboring matrices (PCNM) spatial variables were generated according to the PCNM based on the longitude and latitude of transects and used as spatial factors. Monte Carlo permutation $(n=999)$ and forward selection were used to screen the significant environmental factors and spatial factors $(p<0.05)$ as explanatory variables. Then, we carried out RDA and adopted the adjusted $R^{2}$ value. Variation partitioning was used to understand the explanatory ability of each factor to the structure of phylogeny and functional traits. Multiple regressions on distance matrices (MRM) analysis was used to test the effects of environmental factor distance and 
spatial factor distance on phylogenetic and functional trait beta diversity. MRM entails a multiple regression of a response distance matrix on two or more environmental, spatial, or other explanatory distance matrices, each unfolded into a distance vector. The significance of an MRM model and its regression coefficients are tested by permuting matrices while holding the explanatory matrices constant [54]. Phylogenetic Dpw and Dnn indices were analyzed as response matrices, while environmental factor and spatial factor matrices were regarded as explanatory distance matrices. Furthermore, phylogenetic Dpw and Dnn indices were added as explanatory distance matrices when functional traits' Dpw and Dnn indices were analyzed. MRM analysis could test the correlation between response matrices and explanatory distance matrices, and the Bray-Curtis distance was used as the matrix distance index.

Data calculation was carried out in R 4.0.3 software, and the packages used included "Plantist" [55], "Picante", "SoDA", "packfor", "spacemakeR", "PCNM", "vegan", and "ecodist". R 4.0.3, iTOL v6, SigmaPlot 10.0, and Adobe Illustrator CC 2018 software were used to draw figures.

\section{Results}

\subsection{Phylogenetic Signal}

We analyzed the phylogenetic signal intensity of functional traits by using Blomberg's $\mathrm{K}$ index (Table 1). The results showed that LTC, LTN, LTP, and L C/N and L N/P had significant $p$ values, but Blomberg's K values were lower than 0.8 , which meant that they showed weak phylogenetic signals. Meanwhile, no phylogenetic signals were detected from other traits. Therefore, we found that the accumulation of nutrient elements in leaves had a more obvious phylogenetic signal than other functional traits.

Table 1. Phylogenetic signal intensity of functional traits.

\begin{tabular}{ccccc}
\hline Traits & Blomberg's K & PIC.variance.obs & PIC.variance.rnd.mean & $p$ Value \\
\hline L C/N & 0.603 & 0.000 & 0.000 & $0.050^{*}$ \\
L N/P & 0.700 & 0.001 & 0.001 & $0.009^{* *}$ \\
LTC & 0.703 & 0.000 & 0.000 & $0.012^{*}$ \\
LTN & 0.621 & 0.000 & 0.000 & $0.031^{*}$ \\
LTP & 0.702 & 0.000 & 0.000 & $0.015^{*}$ \\
LTK & 0.553 & 0.000 & 0.000 & 0.078 \\
LW & 0.496 & 0.002 & 0.002 & 0.181 \\
LL & 0.497 & 0.001 & 0.002 & 0.201 \\
LT & 0.348 & 0.000 & 0.000 & 0.560 \\
RCC & 0.529 & 0.000 & 0.000 & 0.109 \\
LA & 0.479 & 0.004 & 0.006 & 0.256 \\
SLA & 0.464 & 0.000 & 0.000 & 0.235 \\
LDMC & 0.357 & 0.000 & 0.000 & 0.503 \\
\hline
\end{tabular}

Note: ${ }^{*} p<0.05,{ }^{* *} p<0.01$, others $p \geq 0.05$.

\subsection{Phylogenetic and Functional Trait Structures along Elevational Gradients}

We found that the phylogenetic SES.MPD showed a trend of lower elevations greater than zero and higher elevations less than zero (Figure 1a), and this was also found for the phylogenetic SES.MNTD (Figure 1b), but the SES values were significant at high elevations only $(<-1.96)$. This result suggested that the phylogenetic structure of woody plants changed from a stochastic process to clustering with increasing elevation. However, the trait SES.MPD showed a unimodal curve pattern that changed from less than zero to greater than zero and then back to less than zero (Figure 1c), and the trait SES.MNTD was significant $(<-1.96)$ at most elevations (Figure 1d); the trend was different from that of the phylogenetic structure. This result suggested that the functional trait structures of woody plants were stochastic, and the trait distributions of relative species showed obvious clustering. 


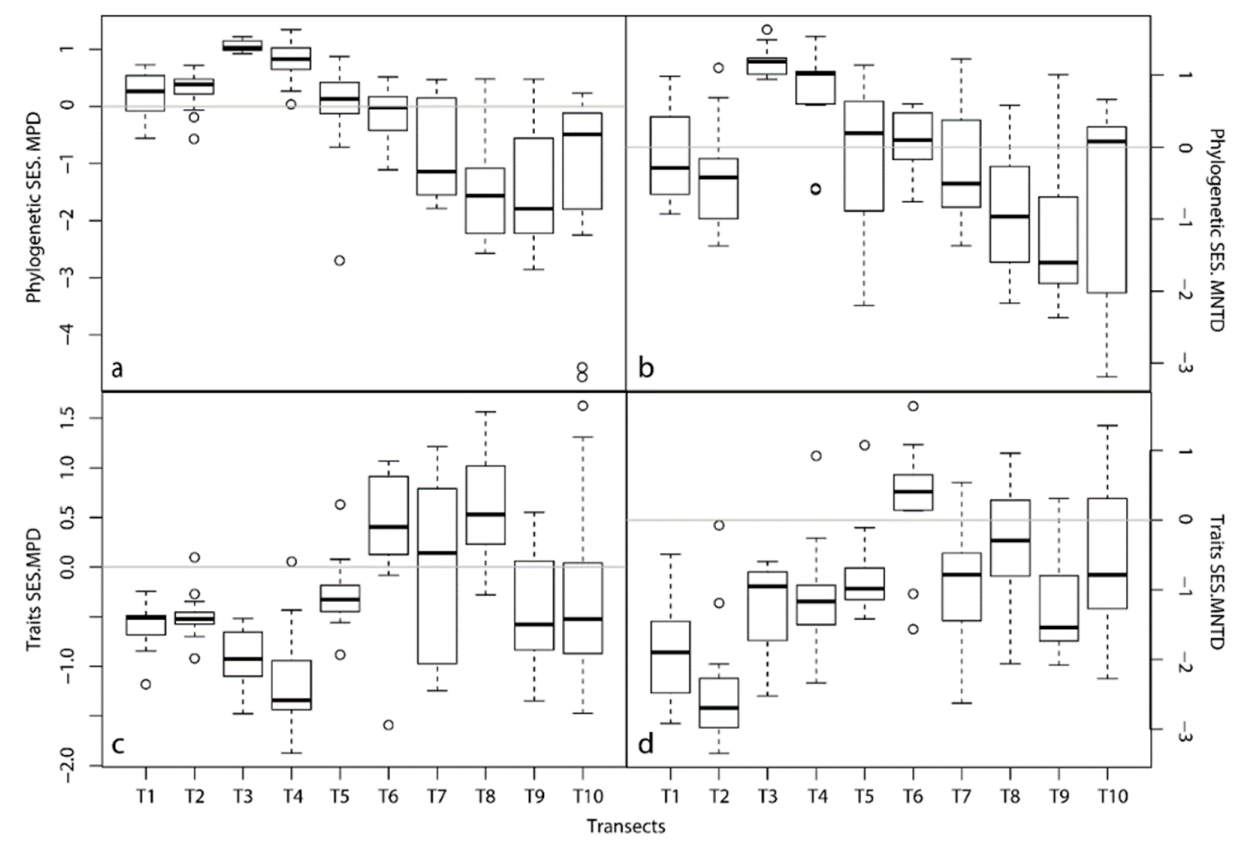

Figure 1. Phylogenetic and functional trait structure along an elevational gradient: (a) phylogenetic SES.MPD, (b) phylogenetic SES.MNTD, (c) trait SES.MPD, and (d) trait SES.MNTD.

\subsection{Phylogenetic and Functional Trait Beta Diversity along an Elevational Gradient}

The phylogenetic SES.Dpw of woody plants at adjacent elevations showed a trend of lower elevations greater than zero and higher elevations lower than zero (Figure 2a), while the beta diversity of the functional traits showed the opposite trend (Figure 2c), and only few SES values were significant $(>1.96$ or $<-1.96)$. The phylogenetic SES.Dnn showed that the extent of evolution was lower than the expected value of a random process and showed random changes along the elevational gradient, and similar results were found for the functional trait SES.Dnn (Figure 2b,d).

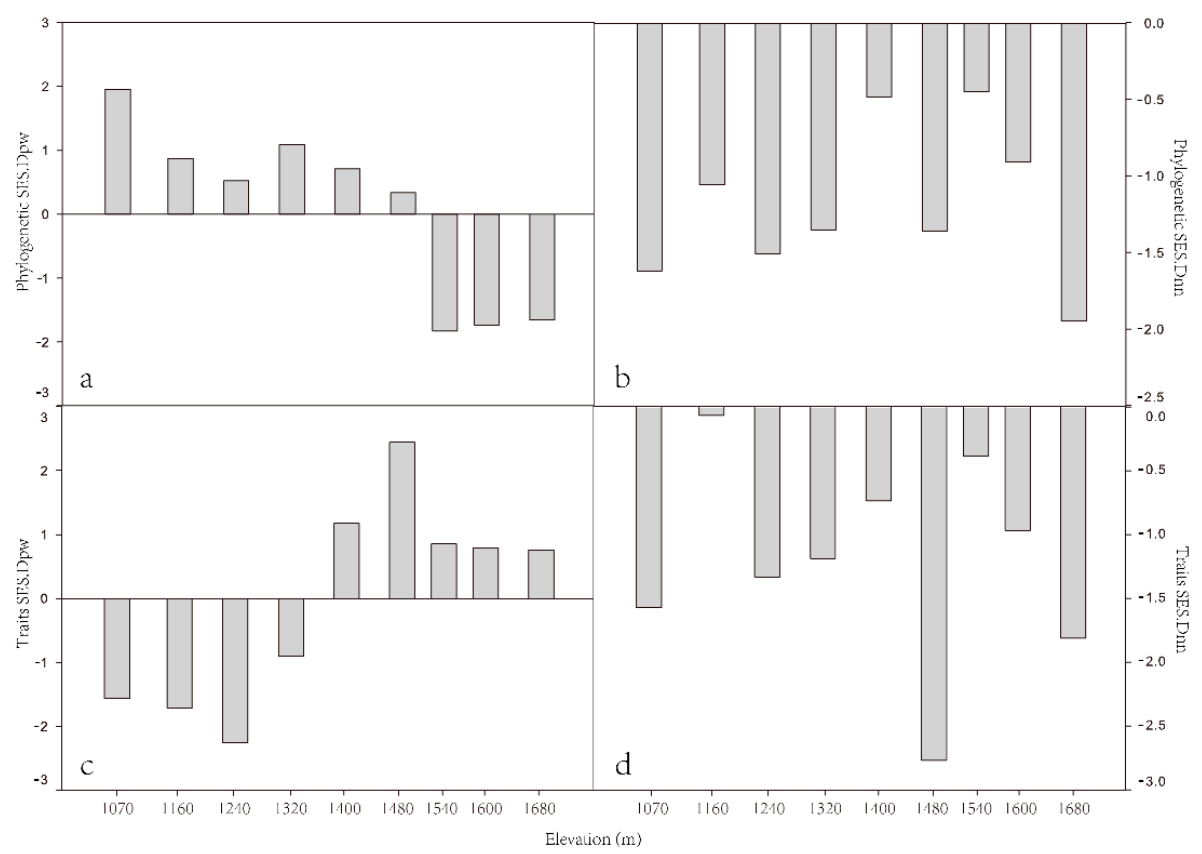

Figure 2. Phylogenetic and functional trait beta diversity along an elevational gradient: (a) phylogenetic SES.Dpw, (b) phylogenetic SES.Dnn, (c) trait SES.Dpw, and (d) trait SES.Dnn. 


\subsection{Environmental Interpretation of Phylogenetic and Functional Traits}

Significant environmental factors were selected as variables through forward selection (Appendix D). The results showed that environmental factors and spatial factors explained $5.4 \%$ and $4.5 \%$ of the variation in the phylogenetic SES.MPD, respectively. The interaction between the environmental and spatial factors explained $35.6 \%$ of the variation, and the unexplained part remained at $54.5 \%$ (Figure 3a). Additionally, both the single interpretation rate and the common interpretation rate were low for the phylogenetic SES.MNTD $($ residual $=0.723)($ Figure $3 b)$.

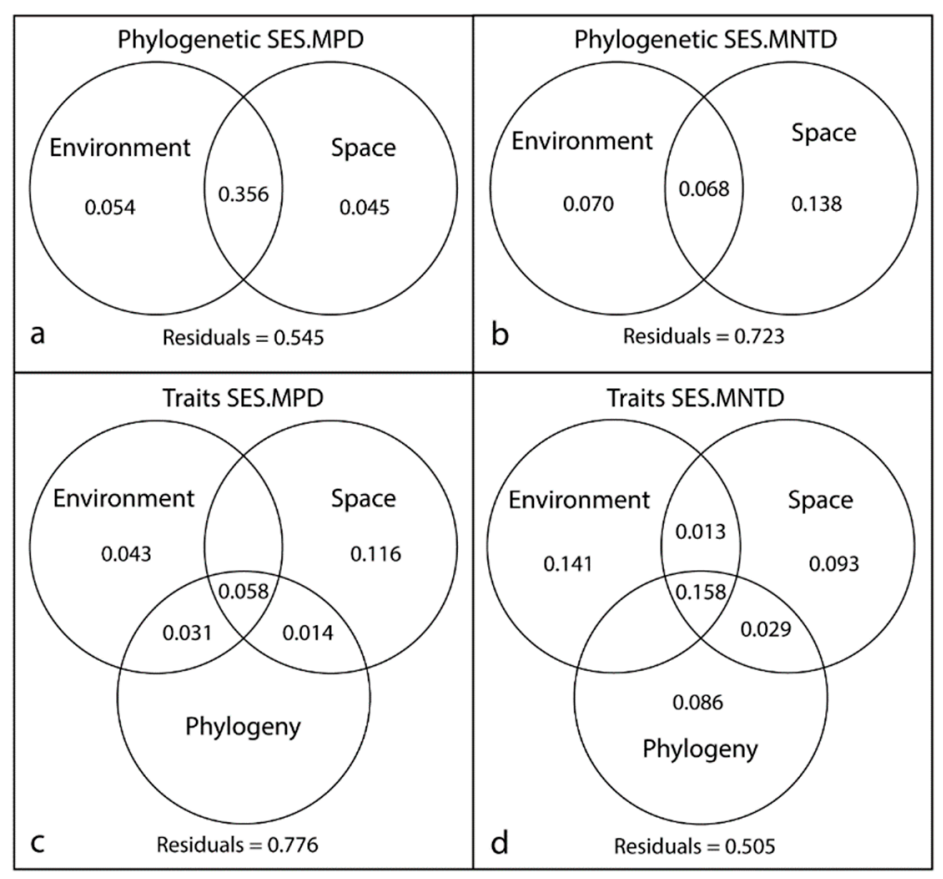

Figure 3. Variation partitioning of phylogenetic and functional trait structures: (a) interpretation rate of environmental factors and spatial factors to phylogenetic SES.MPD; (b) interpretation rate of environmental factors and spatial factors to phylogenetic SES.MNTD; (c) interpretation rate of environmental factors, spatial factors, and phylogenetic factors to trait SES.MPD; and (d) interpretation rate of environmental factors, spatial factors, and phylogenetic factors for trait SES.MNTD. The values represent the independent and common interpretation rate of each factor; null means no explanation and residuals represent the unexplained parts.

To explore the impact of phylogeny on functional traits, we added the phylogenetic structure into the functional traits' RDA as an explanatory variable. The screening method for significant variables was the same as that described above (Appendix D). The results showed that environmental factors explained $4.3 \%$ of the variation in the functional traits SES.MPD, while the spatial factors explained $11.6 \%$ of the variation alone. However, the individual explanatory ability of phylogenetic factors was relatively low. The interaction of the three factors explained $5.8 \%$ of the variation, and the unexplained part remained at $77.6 \%$ (Figure 3c). The functional traits' SES.MNTD and environmental factors explained $14.1 \%$ alone, and the interpretation rates of the spatial and phylogenetic factors were similar ( $9.3 \%$ and $8.6 \%$, respectively). The interaction of the three factors explained $15.8 \%$ of the variation, and the unexplained part remained at $50.5 \%$ (Figure $3 \mathrm{~d}$ ).

We used MRM to test the correlation between the phylogenetic and functional trait distance matrices. The results showed that the spatial and environmental factor distances were both extremely significantly correlated with the phylogenetic beta diversity distance, but the spatial factor distance had a greater influence. The interaction of the two factors also significantly affected the phylogenetic beta diversity between transects. Similarly, to test the impact of phylogeny on functional traits, we added phylogenetic beta diversity to the 
MRM analysis of functional traits as a factor. The results suggested that the phylogenetic beta diversity distance was extremely significantly correlated with the functional trait beta diversity distance. The spatial factor distance had a significant correlation with the beta diversity distance of functional traits, while the environmental factor distance had no significant correlation. Their impact on the beta diversity of functional traits also decreased progressively. Furthermore, the interaction of the three factors significantly affected the beta diversity of the functional traits between transects (Table 2).

Table 2. MRM of beta diversity of phylogenetic and functional traits.

\begin{tabular}{|c|c|c|c|}
\hline Index & Factors & $R^{2}$ & $p$ \\
\hline \multirow{3}{*}{ Phylogenetic Dpw } & Environment & 0.0942 & $0.046^{*}$ \\
\hline & Space & 0.3965 & $0.001^{* * *}$ \\
\hline & Interaction & 0.3967 & $0.002 * *$ \\
\hline \multirow{3}{*}{ Phylogenetic Dnn } & Environment & 0.0149 & 0.430 \\
\hline & Space & 0.3567 & $0.001^{* * *}$ \\
\hline & Interaction & 0.3995 & $0.003^{* *}$ \\
\hline \multirow{4}{*}{ Functional traits' Dpw } & Environment & 0.0079 & 0.646 \\
\hline & Space & 0.1133 & $0.007^{* *}$ \\
\hline & Phylogenetic $\beta$ diversity & 0.4336 & $0.017 *$ \\
\hline & Interaction & 0.4820 & $0.024 *$ \\
\hline \multirow{4}{*}{ Functional traits' Dnn } & Environment & 0 & 0.995 \\
\hline & Space & 0.2901 & $0.001^{* *}$ \\
\hline & Phylogenetic $\beta$ diversity & 0.7410 & $0.001 * *$ \\
\hline & Interaction & 0.7689 & $0.001^{* *}$ \\
\hline
\end{tabular}

\section{Discussion}

Phylogenetics could reflect the complex adaptive strategies or some unmeasured conservative functional traits of species, which are closely related to community assembly mechanisms. Therefore, the method combined with the analysis of phylogenetic and functional traits has become an effective research tool that can be used to evaluate the ecological process of community assembly $[36,46,56]$. Furthermore, this method could complement studies on the relationships between conventional forest stand attributes and structural indices in order to help resolve this issue, which is of high practical importance for forest managers [57,58]. In this study, we analyzed the phylogenetic and functional traits of 30 woody plants along an elevational gradient on Mt. Dongling. The lowest elevation we selected represents the typical low-elevation forest vegetation in this area, while the highest elevation is near the tree line; thus, this elevational gradient is ideal for investigating the phylogenetic patterns and functional traits of woody plant assemblages in the study area [5]. We tested the mechanism of community assembly by the changes in phylogenetic and functional traits along the elevational gradient. The main results showed that the phylogenetic and functional traits exhibited general random component and less nonrandom component transformation along the elevational gradient, indicating that the stochastic hypothesis played the more important role in controlling community transformation.

The effects of elevation on phylogenetic and functional traits have been proven in many studies. In general, the structure of phylogenetic and functional traits changed regularly along the elevational gradient, including consistent and inconsistent changes [46,59]. Many studies found that competitive exclusion leads to the overdispersion of phylogenetic (functional) structure, while environmental filtering leads to clustering [60-62]. Some studies have suggested that the relative importance of competitive exclusion in high elevational areas is greater than that of environmental filtering [63,64], but our research showed the opposite result. We found that the significant phylogenetic SES values (less than -1.96) appeared in the high-elevation area; they showed that the woody plants were clustered and indicated that the environmental filtering significantly affected the distribution of woody 
plants. The clustering of relative species at high elevations also confirmed this conclusion. However, the traits' SES values showed considerable randomness, which suggested that the change in elevation in this area did not cause significant differences in the functional traits of woody species, perhaps because the change in elevation was not correlated with great changes to the environment or because the degree of environmental change has not high enough to cause a different response among woody species. In addition, functional traits SES.MNTD values were less than zero and greater than -1.96 along most of the elevational gradient, indicating that the response of the traits of relative species to environmental changes were similar, and the change in elevation had no obvious effect on the traits of relative species.

The beta diversity also differed between phylogenetic and functional traits. Most SES values of structure and beta diversity were not significant (between -1.96 and 1.96), indicating that only a few elevations had deterministic processes, and there were many random effects in the community assembly of this region. Although most of the SES values were not significant (indicating the dominant role of randomness), the SES.Dpw showed a completely opposite change trend, and the SES.Dnn showed a similar trend; furthermore, the results were not consistent with our hypotheses. Several studies suggested that the changes between phylogenetic and functional traits were relatively independent, but others showed a high correlation $[65,66]$. A study also suggested that the beta diversity of functional traits increases with elevation [52]. It is worth noting that the beta diversity was significant in both some low-elevation and high-elevation regions. Combined with the overall trend, we considered that elevation gradient had a certain impact on phylogenetic and functional traits, which led to the opposite changes, but most of the changes did not reach a significant degree of difference. Furthermore, the SES.Dnn showed a similar negative curve, which indicated that the variation along the elevation gradient had few impacts on the phylogenetic and functional traits of relative species. This is also consistent with the results of structure analysis. One study indicated that phylogenetic diversity may be used as a crude surrogate measure of functional diversity [67], but we concluded that phylogenetic diversity should not be used as a surrogate of functional diversity since the change trends in functional traits differed with phylogeny.

Stronger environmental filtering leads to phylogenetic clustering that is easier than competition exclusion when functional traits with significant phylogenetic signals participate in the community assembly process [63]. Another study demonstrated that the competition pressure of species was a crucial factor driving and regulating the distribution of biomass [68]. We detected the phylogenetic signals of 13 kinds of leaf functional traits, and the elemental contents showed some weak phylogenetic signals. The signals of elemental contents were relatively significant, which was similar to the results of other studies $[46,67,69]$. Combined with the changes in phylogenetic and functional traits along the elevational gradient, the results also verified our study. The accumulation of nutrient elements in plant leaves more easily showed obvious signals of phylogeny than other functional traits, which indicated that the influences of phylogeny on the functional traits of woody plant leaves might originate from changing the accumulation of nutrient substances. In addition, the insensitivity of functional traits to phylogenetic signals shown in our results might be related to the selection of traits directly.

The change in species along the environmental gradient was not only due to diffusion limitations but also due to the underlying environmental gradient that plays a pivotal role in species replacement and community assembly $[52,70,71]$. Several studies have confirmed that an important part of the abiotic environment cannot always be clearly quantified due to strong spatial autocorrelation $[15,34,72]$. To verify the effect of the deterministic process, we screened and analyzed the interpretive abilities of environmental factors to phylogenetic and functional traits. The mountainous environment provided a natural laboratory for exploring the relationship among environmental variables, spatial variables, and elevational gradient diversity [73]. Our studies indicated that both environmental and spatial variables could explain phylogenetic and functional traits to a certain extent, 
which also verified our hypothesis, but phylogeny had a low explanation rate for the functional trait structure. One study showed that spatial and environmental variables determined the structure of community functional traits, while phylogenetic information had little influence [74]; the results were consistent with ours. Furthermore, we found that the trait variation of relative species was related to environmental conditions, spatial changes, and phylogenetic structure of species through the high explanation rate for the SES.MNTD. In general, the variation in phylogenetic and functional trait structure was clearly related to the abiotic environment, which also strengthened the support of our hypothesis. Additionally, abiotic environmental filtering could not explain the community assembly process entirely. We suggested that the phylogeny showed a lesser impact on functional traits, and the high residuals in variation partitioning might also confirm the existence of environmental factors and random effects that have not been considered.

It has been found that the interaction between abiotic environmental gradients dominates the variation in beta diversity in phylogenetic and functional traits [24]. Different species have their own distribution range along the elevational gradient, and spatial location, seed diffusion, environmental conditions, and other factors limit the expansion of species in the new environment $[75,76]$. Plants at different elevations will be affected by their own genes and spatial conditions, and with changes in their surroundings, they will experience corresponding changes in functional traits to adapt to the current habitats. The results of MRM analysis also showed that there were close correlations among environmental variables, spatial variables, and phylogenetic and functional traits, which confirmed our hypothesis. However, how phylogeny affects functional traits remains to be further analyzed from the perspective of molecular biology.

\section{Conclusions}

In this study, we used the structure and beta diversity of phylogenetic and functional traits to test the hypotheses of their relationship. The results suggested that the change patterns of phylogenetic and functional traits varied due to the different main drivers of community evolution, but strong random effects were found at most elevational gradients, and the combined effect of deterministic processes and stochastic hypotheses (with the primary role of stochastic processes) guided community assembly along the elevational gradient. Additionally, the weak phylogenetic signals indicated the slight effect of phylogeny on the selected functional traits along the elevational gradient. The variation in phylogenetic and functional trait structure had a certain correlation to the abiotic environment, but abiotic environment filtering could not explain the community assembly process entirely. Elevation gradient had a certain impact on phylogenetic and functional traits, but most of the changes did not reach a significant degree of difference. Our study emphasized the importance of joint research on phylogenetic and functional traits when exploring the complex mechanisms driving community assembly.

Author Contributions: Y.Z. and K.M. contributed to the conception of the study. W.Z. performed the experiment and data analyses, and wrote the manuscript. B.N.Y. and S.Z. helped perform the analysis with constructive discussions. All authors have read and agreed to the published version of the manuscript.

Funding: This research was funded by National Natural Science Foundation of China (32071543), the National Key Research and Development Program of China (2016YFC0503003), the National Natural Science Foundation of China (31611130031 and 31370451), the Innovation Project of the State Key Laboratory of Urban and Regional Ecology of China, and the Russian Foundation for Basic Research (projects 18-04-00673 and 19-04-01084).

Institutional Review Board Statement: Not applicable.

Informed Consent Statement: Not applicable.

Data Availability Statement: The data presented in this study are available on request from the corresponding author. The data are not publicly available due to privacy restriction. 
Acknowledgments: We are grateful to all the students from Tianjin Chengjian University and Beijing Forestry University for their help with field data collection and laboratory experimental work. We also thank Ran Wu from Zhejiang University for her help with data analysis.

Conflicts of Interest: The authors declare no conflict of interest.

\section{Appendix A}

Table A1. Transect information.

\begin{tabular}{ccccc}
\hline Transect & Elevation Range & Transect Width & Transect Length & Number of Quadrats \\
\hline T1 & $1020-1055 \mathrm{~m}$ & $10 \mathrm{~m}$ & $80 \mathrm{~m}$ & 8 \\
T2 & $1060-1160 \mathrm{~m}$ & $10 \mathrm{~m}$ & $180 \mathrm{~m}$ & 18 \\
T3 & $1170-1240 \mathrm{~m}$ & $10 \mathrm{~m}$ & $90 \mathrm{~m}$ & 9 \\
T4 & $1250-1320 \mathrm{~m}$ & $10 \mathrm{~m}$ & $130 \mathrm{~m}$ & 13 \\
T5 & $1330-1395 \mathrm{~m}$ & $10 \mathrm{~m}$ & $110 \mathrm{~m}$ & 11 \\
T6 & $1400-1480 \mathrm{~m}$ & $10 \mathrm{~m}$ & $140 \mathrm{~m}$ & 14 \\
T7 & $1490-1540 \mathrm{~m}$ & $10 \mathrm{~m}$ & $80 \mathrm{~m}$ & 8 \\
T8 & $1546-1600 \mathrm{~m}$ & $10 \mathrm{~m}$ & $100 \mathrm{~m}$ & 10 \\
T9 & $1610-1670 \mathrm{~m}$ & $10 \mathrm{~m}$ & $110 \mathrm{~m}$ & 11 \\
T10 & $1676-1770 \mathrm{~m}$ & $10 \mathrm{~m}$ & $170 \mathrm{~m}$ & 17 \\
\hline
\end{tabular}

\section{Appendix B}

Table A2. Selection of leaf functional traits.

\begin{tabular}{|c|c|c|c|}
\hline Category & Functional Traits & Performance & Unit \\
\hline \multirow{6}{*}{$\begin{array}{l}\text { Chemical properties } \\
\text { of leaf }\end{array}$} & $\begin{array}{l}\text { Leaf total carbon content } \\
\text { (LTC) }\end{array}$ & $\begin{array}{l}\text { Related to the cost of leaf construction, } \\
\text { reflecting the growth and development } \\
\text { of plants }\end{array}$ & $\mathrm{mg} / \mathrm{g}$ \\
\hline & $\begin{array}{l}\text { Leaf total nitrogen content } \\
\text { (LTN) }\end{array}$ & $\begin{array}{l}\text { Related to the metabolism and energy } \\
\text { flow of leaves, reflecting the growth } \\
\text { and development of plants }\end{array}$ & $\mathrm{mg} / \mathrm{g}$ \\
\hline & $\begin{array}{l}\text { Leaf total phosphorus content } \\
\text { (LTP) }\end{array}$ & $\begin{array}{l}\text { Related to the metabolism and energy } \\
\text { flow of leaves, reflecting the growth } \\
\text { and development of plants }\end{array}$ & $\mathrm{mg} / \mathrm{g}$ \\
\hline & $\begin{array}{l}\text { Leaf total potassium content } \\
\text { (LTK) }\end{array}$ & $\begin{array}{l}\text { Related to the metabolism and energy } \\
\text { flow of leaves, reflecting the growth } \\
\text { and development of plants }\end{array}$ & $\mathrm{mg} / \mathrm{g}$ \\
\hline & $\begin{array}{l}\text { Ratio of carbon to nitrogen of leaf } \\
(\mathrm{L} \mathrm{C} / \mathrm{N})\end{array}$ & $\begin{array}{l}\text { Reflects the utilization efficiency and } \\
\text { restriction of plant nutrients }\end{array}$ & - \\
\hline & $\begin{array}{l}\text { Ratio of nitrogen to phosphorus of leaf } \\
\qquad(\mathrm{L} \mathrm{N} / \mathrm{P})\end{array}$ & $\begin{array}{l}\text { Reflects the utilization efficiency and } \\
\text { restriction of plant nutrients }\end{array}$ & - \\
\hline \multirow{6}{*}{$\begin{array}{l}\text { Physical properties } \\
\text { of leaf }\end{array}$} & Leaf area (LA) & $\begin{array}{l}\text { Access to light resources and water } \\
\text { use capacity }\end{array}$ & $\mathrm{cm}^{2}$ \\
\hline & Specific leaf area (SLA) & $\begin{array}{l}\text { Indicates plant's input-output tradeoff } \\
\text { and leaf life cycle }\end{array}$ & $\mathrm{cm}^{2} / \mathrm{g}$ \\
\hline & Leaf length (LL) & $\begin{array}{l}\text { Access to light resources and water } \\
\text { use capacity }\end{array}$ & $\mathrm{cm}$ \\
\hline & Leaf width (LW) & $\begin{array}{c}\text { Access to light resources and water } \\
\text { use capacity }\end{array}$ & $\mathrm{cm}$ \\
\hline & Leaf thickness (LT) & $\begin{array}{l}\text { Closely related to defense, degradation, } \\
\text { and nutrient cycle of leaves }\end{array}$ & $\mathrm{mm}$ \\
\hline & Leaf dry matter content (LDMC) & $\begin{array}{l}\text { Represents the ability to obtain } \\
\text { resources, affecting the mechanical } \\
\text { strength and flammability }\end{array}$ & $\mathrm{mg}$ \\
\hline Photosynthetic capacity of leaf & Chlorophyll content (RCC) & $\begin{array}{c}\text { Reflects the photosynthetic capacity } \\
\text { of plants }\end{array}$ & $\mathrm{mg} / \mathrm{g}$ \\
\hline
\end{tabular}




\section{Appendix C}

Table A3. The appearance of woody plants in each transect.

\begin{tabular}{|c|c|c|c|c|c|c|c|c|c|c|c|}
\hline \multirow[t]{2}{*}{ Species } & \multirow[t]{2}{*}{ Family } & \multicolumn{10}{|c|}{ Transects } \\
\hline & & T1 & $\mathrm{T} 2$ & T3 & $\mathrm{T} 4$ & T5 & T6 & $\mathrm{T} 7$ & T8 & T9 & T10 \\
\hline Tree & & & & & & & & & & & \\
\hline Quercus wutaishanica Blume & Fagaceae & $\mathbf{\square}$ & $\mathbf{\square}$ & $\mathbf{\square}$ & $\mathbf{\square}$ & $\mathbf{\square}$ & $\mathbf{\square}$ & $\mathbf{\square}$ & $\mathbf{\square}$ & $\mathbf{\square}$ & $\mathbf{\square}$ \\
\hline Fraxinus chinensis Roxb. & Oleaceae & $\bar{\square}$ & 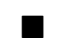 & $\bar{\square}$ & $\bar{\square}$ & $\bar{\square}$ & $\bar{\square}$ & $\bar{\square}$ & $\bar{\square}$ & $\square$ & $\square$ \\
\hline Acer mono Maxim. & Aceraceae & $\square$ & $\square$ & $\overline{\mathbf{\square}}$ & $\overline{\mathbf{\square}}$ & $\overline{\mathbf{\square}}$ & $\overline{\mathbf{\square}}$ & $\overline{\mathbf{\square}}$ & $\square$ & $\bar{\square}$ & $\mathbf{\square}$ \\
\hline Syringa oblata Lindl. & Oleaceae & $\mathbf{\square}$ & $\square$ & $\square$ & $\mathbf{\square}$ & $\mathbf{\square}$ & $\square$ & $\mathbf{\square}$ & $\mathbf{\square}$ & $\square$ & $\square$ \\
\hline $\begin{array}{l}\text { Ulmus davidiana var. japonica } \\
\text { (Rehd.) Nakai }\end{array}$ & Ulmaceae & 口 & 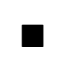 & $\square$ & $\square$ & $\square$ & $\square$ & $\mathbf{\square}$ & $\mathbf{\square}$ & $\mathbf{\square}$ & $\mathbf{\square}$ \\
\hline Ulmus macrocarpa Hance & Ulmaceae & $\mathbf{\square}$ & Q & $\mathbf{\square}$ & $\square$ & $\mathbf{\square}$ & $\square$ & $\mathbf{\square}$ & $\mathbf{\square}$ & $\mathbf{\square}$ & $\square$ \\
\hline Betula dahurica Pall. & Betulaceae & $\overline{\mathbf{\square}}$ & $\overline{\vec{n}}$ & $\overline{\mathbf{a}}$ & $\mathbf{\square}$ & $\bar{\square}$ & $\mathbf{\square}$ & $\overline{\mathbf{a}}$ & $\overline{\mathbf{a}}$ & $\overline{\mathbf{a}}$ & $\mathbf{\square}$ \\
\hline $\begin{array}{l}\text { Syringa reticulata var. amurensis } \\
\text { (Ruprecht)P.S.Green \& M.C.Chang }\end{array}$ & Oleaceae & $\square$ & $\square$ & $\square$ & $\square$ & $\square$ & $\square$ & $\square$ & $\mathbf{\square}$ & $\mathbf{\square}$ & $\square$ \\
\hline Juglans mandshurica Maxim. & Juglandaceae & $\square$ & $\square$ & $\mathbf{\square}$ & $\square$ & $\mathbf{\square}$ & $\square$ & $\square$ & $\square$ & $\square$ & $\square$ \\
\hline Ulmus laciniata (Trautv.) Mayr & Ulmaceae & $\square$ & $\square$ & $\overline{\mathbf{a}}$ & $\square$ & $\bar{\square}$ & $\square$ & $\square$ & $\square$ & $\square$ & $\square$ \\
\hline Tilia mongolica Maxim. & Tiliaceae & $\square$ & $\square$ & $\mathbf{\square}$ & $\square$ & $\square$ & $\square$ & $\square$ & $\square$ & $\square$ & $\square$ \\
\hline Amygdalus davidiana (Carr.) C. de Vos & Rosaceae & $\mathbf{\square}$ & $\mathbf{a}$ & $\square$ & $\square$ & $\mathbf{a}$ & $\square$ & $\square$ & $\square$ & $\square$ & $\square$ \\
\hline Populus davidiana Dode & Salicaceae & $\square$ & $\mathbf{\square}$ & $\mathbf{\square}$ & $\square$ & $\square$ & $\mathbf{\square}$ & $\square$ & $\square$ & $\square$ & $\square$ \\
\hline Ulmus pumila L. & Ulmaceae & $\square$ & $\square$ & $\overline{\mathbf{\square}}$ & $\square$ & $\square$ & $\overline{\mathbf{\square}}$ & $\square$ & $\square$ & $\square$ & $\square$ \\
\hline $\begin{array}{c}\text { Tilia amurensis Rupr. } \\
\text { Shrub }\end{array}$ & Tiliaceae & $\mathbf{a}$ & $\square$ & $\bar{\square}$ & $\square$ & $\mathbf{a}$ & $\bar{\square}$ & $\square$ & $\square$ & $\square$ & $\square$ \\
\hline Spiraea trilobata $\mathrm{L}$. & Rosaceae & $\mathbf{\square}$ & $\mathbf{\square}$ & $\mathbf{\square}$ & $\mathbf{\square}$ & $\mathbf{\square}$ & $\mathbf{\square}$ & $\mathbf{\square}$ & $\mathbf{\square}$ & $\mathbf{\square}$ & $\mathbf{\square}$ \\
\hline Spiraea pubescens Turcz. & Rosaceae & & $\mathbf{\square}$ & $\square$ & $\square$ & $\bar{\square}$ & $\square$ & $\bar{\square}$ & $\bar{\square}$ & $\bar{\square}$ & $\mathbf{\square}$ \\
\hline Abelia biflora Turcz. & Caprifoliaceae & 0 & $\mathbf{\square}$ & $\mathbf{\square}$ & $\mathbf{\square}$ & $\mathbf{\square}$ & $\mathbf{\square}$ & $\mathbf{\square}$ & $\square$ & $\square$ & $\square$ \\
\hline Deutzia parviflora Bge. & Saxifragaceae & $\mathbf{\square}$ & $\mathbf{\square}$ & $\mathbf{\square}$ & $\mathbf{\square}$ & $\mathbf{\square}$ & $\square$ & $\mathbf{\square}$ & $\square$ & $\mathbf{\square}$ & $\bar{\square}$ \\
\hline Lespedeza bicolor Turcz. & Leguminosae & $\mathbf{\square}$ & $\mathbf{\square}$ & $\mathbf{\square}$ & $\mathbf{\square}$ & $\mathbf{\square}$ & $\square$ & $\overline{\mathbf{a}}$ & $\mathbf{\square}$ & $\overline{\mathbf{a}}$ & $\overline{\mathbf{a}}$ \\
\hline Ostryopsis davidiana Decaisne & Betulaceae & $\square$ & $\mathbf{\square}$ & $\square$ & $\square$ & $\square$ & $\square$ & $\square$ & $\square$ & $\square$ & $\square$ \\
\hline Lonicera chrysantha Turcz. & Caprifoliaceae & $\square$ & $\square$ & $\square$ & $\square$ & $\square$ & $\square$ & $\square$ & $\mathbf{\square}$ & $\square$ & $\square$ \\
\hline Corylus mandshurica Maxim. & Betulaceae & $\square$ & $\square$ & $\square$ & $\square$ & $\square$ & $\overline{\mathbf{a}}$ & $\square$ & $\overline{\mathbf{\square}}$ & $\overline{\mathbf{a}}$ & $\mathbf{\square}$ \\
\hline Rubus crataegifolius Bge. & Rosaceae & $\square$ & $\square$ & $\square$ & $\square$ & $\overline{\mathbf{\square}}$ & $\overrightarrow{\mathbf{a}}$ & $\square$ & $\square$ & $\square$ & $\square$ \\
\hline Leptopus chinensis (Bunge) Pojark. & Euphorbiaceae & $\square$ & $\square$ & $\square$ & $\square$ & $\square$ & $\square$ & $\mathbf{\square}$ & $\square$ & $\square$ & $\square$ \\
\hline Philadelphus pekinensis Rupr. & Saxifragaceae & $\mathbf{\square}$ & $\square$ & $\square$ & $\square$ & $\mathbf{\square}$ & $\square$ & $\square$ & $\square$ & $\square$ & $\square$ \\
\hline Euonymus alatus (Thunb.) Sieb. & Celastraceae & $\square$ & $\square$ & $\square$ & $\square$ & $\mathbf{\square}$ & $\square$ & $\square$ & $\square$ & $\square$ & $\square$ \\
\hline Syringa villosa Vahl & Oleaceae & $\mathbf{\square}$ & $\square$ & $\square$ & $\mathbf{\square}$ & $\bar{\square}$ & $\square$ & $\square$ & $\square$ & $\square$ & $\square$ \\
\hline Rhamnus globosa Bunge & Rhamnaceae & $\overline{\mathbf{a}}$ & $\square$ & $\square$ & $\bar{\square}$ & $\square$ & $\square$ & $\mathbf{\square}$ & $\mathbf{\square}$ & $\mathbf{\square}$ & $\mathbf{\square}$ \\
\hline Rhododendron micranthum Turcz. & Ericaceae & $\mathbf{\square}$ & $\mathbf{\square}$ & $\square$ & $\mathbf{\square}$ & $\mathbf{\square}$ & $\square$ & $\square$ & $\square$ & $\square$ & $\square$ \\
\hline Number of Species & & $\overline{17}$ & 15 & 14 & $\overline{12}$ & $\overline{17}$ & 10 & 14 & 13 & 12 & 10 \\
\hline
\end{tabular}

Note: " $\mathbf{\square}$ " indicates that the species is distributed in the transect; " $\square$ " indicates that the species is not distributed in the transect.

\section{Appendix D}

Table A4. Forward selection results of environmental factors and spatial factors.

\begin{tabular}{ccccc}
\hline Index & Factors & Variables & Adj. $\boldsymbol{R}^{\mathbf{2}}$ & $p$ \\
\hline \multirow{2}{*}{ Phylogenetic SES.MPD } & Environment & Elevation & & $0.001^{* * *}$ \\
& Soil Temperature & Soil $\mathrm{pH}$ & 0.396 & $0.001^{* * *}$ \\
\hline Phylogenetic & PCNM1 & Elevation & 0.404 & $0.001^{* * *}$ \\
SES.MNTD & Environment & Soil Temperature & 0.223 & $0.001^{* * *}$ \\
\hline
\end{tabular}


Table A4. Cont.

\begin{tabular}{ccccc}
\hline Index & Factors & Variables & Adj. $\mathbf{R}^{\mathbf{2}}$ & $p$ \\
& Environment & Elevation & 0.081 & $0.005^{* *}$ \\
Traits SES.MPD & Space & PCNM1 & 0.064 & $0.006^{* *}$ \\
& Phylogeny & SES.MPD & 0.061 & $0.022^{* *}$ \\
& & SES.MNTD & 0.101 & $0.033 *$ \\
Traits SES.MNTD & Environment & Soil moisture content & 0.312 & $0.017^{*}$ \\
& & Soil C/N & 0.040 & $0.031^{*}$ \\
& Space & PCNM1 & $0.040 *$ \\
\hline
\end{tabular}

Note: ${ }^{*} p<0.05,{ }^{* *} p<0.01,{ }^{* * *} p<0.005$, others $p \geq 0.05$.

\section{Appendix E}

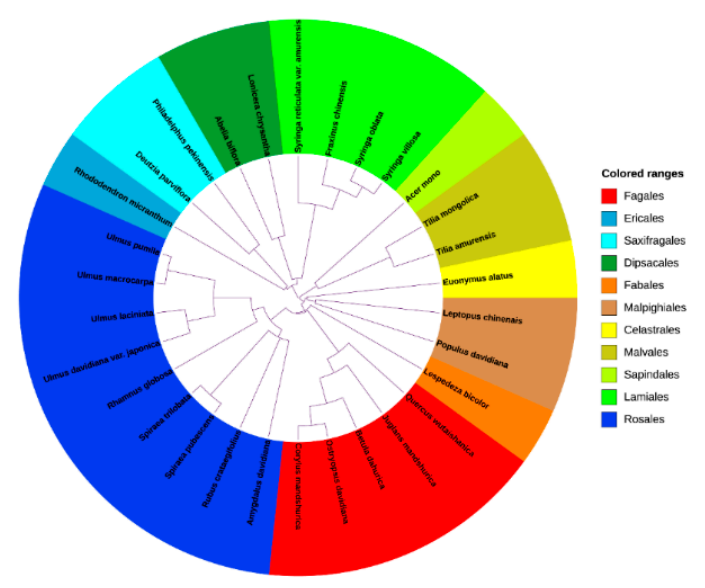

Figure A1. Phylogenetic tree of 30 woody plants. The classification of species was based on the APG IV system; different colors represent different orders.

\section{References}

1. Ricklefs, R.E. A comprehensive framework for global patterns in biodiversity. Ecol. Lett. 2004, 7, 1-15. [CrossRef]

2. Cavender-Bares, J.; Kozak, K.H.; Fine, P.V.A.; Kembel, S.W. The merging of community ecology and phylogenetic biology. Ecol. Lett. 2009, 12, 693-715. [CrossRef] [PubMed]

3. Tilman, D. Niche tradeoffs, neutrality, and community structure: A stochastic theory of resource competition, invasion, and community assembly. Proc. Natl. Acad. Sci. USA 2004, 101, 10854-10861. [CrossRef] [PubMed]

4. Hubbell, S.P. The Unified Neutral Theory of Biodiversity and Biogeography; Princeton University Press: Princeton, NJ, USA, 2001. [CrossRef]

5. Qian, H.; Hao, Z.; Zhang, J. Phylogenetic structure and phylogenetic diversity of angiosperm assemblages in forests along an elevational gradient in Changbaishan, China. J. Plant Ecol. 2014, 7, 154-165. [CrossRef]

6. Hubbell, S.P. Neutral theory in community ecology and the hypothesis of functional equivalence. Funct. Ecol. 2005, 19, 166-172. [CrossRef]

7. Alonso, D.; McKane, A.J. Sampling Hubbell's neutral theory of biodiversity. Ecol. Lett. 2004, 7, 901-910. [CrossRef]

8. Wennekes, P.L.; Rosindell, J.; Etienne, R.S. The Neutral-Niche Debate: A Philosophical Perspective. Acta Biotheor. 2012, 60, 257-271. [CrossRef] [PubMed]

9. Chase, J.M. Drought mediates the importance of stochastic community assembly. Proc. Natl. Acad. Sci. USA 2007, 104, 17430-17434. [CrossRef]

10. Chase, J.M.; Myers, J.A. Disentangling the importance of ecological niches from stochastic processes across scales. Philos. Trans. R. Soc. B Biol. Sci. 2011, 366, 2351-2363. [CrossRef]

11. Condamine, F.L.; Sperling, F.A.H.; Wahlberg, N.; Rasplus, J.-Y.; Kergoat, G.J. What causes latitudinal gradients in species diversity? Evolutionary processes and ecological constraints on swallowtail biodiversity. Ecol. Lett. 2012, 15, 267-277. [CrossRef] [PubMed] 
12. Read, Q.D.; Moorhead, L.C.; Swenson, N.G.; Bailey, J.K.; Sanders, N.J. Convergent effects of elevation on functional leaf traits within and among species. Funct. Ecol. 2013, 28, 37-45. [CrossRef]

13. Jump, A.S.; Mátyás, C.; Peñuelas, J. The altitude-for-latitude disparity in the range retractions of woody species. Trends Ecol. Evol. 2009, 24, 694-701. [CrossRef]

14. Willis, C.G.; Halina, M.; Lehman, C.; Reich, P.B.; Keen, A.; McCarthy, S.; Cavender-Bares, J. Phylogenetic community structure in Minnesota oak savanna is influenced by spatial extent and environmental variation. Ecography 2010, 33, 565-577. [CrossRef]

15. Swenson, N.G.; Enquist, B.J. Ecological and evolutionary determinants of a key plant functional trait: Wood density and its community-wide variation across latitude and elevation. Am. J. Bot. 2007, 94, 451-459. [CrossRef] [PubMed]

16. Shrestha, M.; Dyer, A.G.; Bhattarai, P.; Burd, M. Flower colour and phylogeny along an altitudinal gradient in the Himalayas of Nepal. J. Ecol. 2013, 102, 126-135. [CrossRef]

17. Yu, S.; Katz, O.; Fang, W.; Li, D.; Sang, W.; Liu, C. Shift of fleshy fruited species along elevation: Temperature, canopy coverage, phylogeny and origin. Sci. Rep. 2017, 7, 40417. [CrossRef]

18. Arnold, S.E.J.; Savolainen, V.; Chittka, L. Flower colours along an alpine altitude gradient, seen through the eyes of fly and bee pollinators. Arthropod Plant Interact. 2009, 3, 27-43. [CrossRef]

19. Nakadai, R.; Murakami, M.; Hirao, T. Effects of phylogeny, leaf traits, and the altitudinal distribution of host plants on herbivore assemblages on congeneric Acer species. Oecologia 2014, 175, 1237-1245. [CrossRef] [PubMed]

20. Smith, M.A.; Hallwachs, W.; Janzen, D.H. Diversity and phylogenetic community structure of ants along a Costa Rican elevational gradient. Ecography 2014, 37, 720-731. [CrossRef]

21. Rapai, S.B.; McMullin, R.T.; Newmaster, S.G. The importance of macrolichen traits and phylogeny in forest community assemblage along a high elevation gradient in southwestern British Columbia. For. Ecol. Manag. 2012, 274, 231-240. [CrossRef]

22. Bletz, M.C.; Archer, H.; Harris, R.N.; McKenzie, V.J.; Rabemananjara, F.C.E.; Rakotoarison, A.; Vences, M. Host Ecology Rather Than Host Phylogeny Drives Amphibian Skin Microbial Community Structure in the Biodiversity Hotspot of Madagascar. Front. Microbiol. 2017, 8, 1530. [CrossRef] [PubMed]

23. Chun, J.-H.; Lee, C.-B. Disentangling the local-scale drivers of taxonomic, phylogenetic and functional diversity in woody plant assemblages along elevational gradients in South Korea. PLoS ONE 2017, 12, e0185763. [CrossRef] [PubMed]

24. López-Angulo, J.; Swenson, N.G.; Cavieres, L.A.; Escudero, A. Interactions between abiotic gradients determine functional and phylogenetic diversity patterns in Mediterranean-type climate mountains in the Andes. J. Veg. Sci. 2018, 29, 245-254. [CrossRef]

25. Pellissier, L.; Alvarez, N.; Espíndola, A.; Pottier, J.; Dubuis, A.; Pradervand, J.-N.; Guisan, A. Phylogenetic alpha and beta diversities of butterfly communities correlate with climate in the western Swiss Alps. Ecography 2012, 36, 541-550. [CrossRef]

26. Bryant, J.A.; Lamanna, C.; Morlon, H.; Kerkhoff, A.J.; Enquist, B.J.; Green, J.L. Microbes on mountainsides: Contrasting elevational patterns of bacterial and plant diversity. Proc. Natl. Acad. Sci. USA 2008, 105 (Suppl. S1), 11505-11511. [CrossRef]

27. Violle, C.; Reich, P.B.; Pacala, S.W.; Enquist, B.J.; Kattge, J. The emergence and promise of functional biogeography. Proc. Natl. Acad. Sci. USA 2014, 111, 13690-13696. [CrossRef] [PubMed]

28. Swenson, N.G.; Enquist, B.J.; Thompson, J.; Zimmerman, J.K. The Influence of Spatial and Size Scale on phylogenetic relatedness in Tropical Forest Communities. Ecology 2007, 88, 1770-1780. [CrossRef] [PubMed]

29. Hao, M.H.; Zhang, C.; Zhao, X.; Von Gadow, K. Functional and phylogenetic diversity determine woody productivity in a temperate forest. Ecol. Evol. 2018, 8, 2395-2406. [CrossRef] [PubMed]

30. Flynn, D.F.B.; Mirotchnick, N.; Jain, M.; Palmer, M.I.; Naeem, S. Functional and phylogenetic diversity as predictors of biodiversityecosystem-function relationships. Ecology 2011, 92, 1573-1581. [CrossRef]

31. Wright, I.J.; Reich, P.B.; Westoby, M.; Ackerly, D.; Baruch, Z.; Bongers, F.; Cavender-Bares, J.; Chapin, T.; Cornelissen, J.H.C.; Diemer, M.; et al. The worldwide leaf economics spectrum. Nature 2004, 428, 821-827. [CrossRef]

32. Asner, G.P.; Martin, R.E.; Anderson, C.B.; Kryston, K.; Vaughn, N.; Knapp, D.E.; Bentley, L.P.; Shenkin, A.; Salinas, N.; Sinca, F.; et al. Scale dependence of canopy trait distributions along a tropical forest elevation gradient. New Phytol. 2017, 214, 973-988. [CrossRef] [PubMed]

33. Webb, C.O.; Ackerly, D.D.; McPeek, M.A.; Donoghue, M.J. Phylogenies and Community Ecology. Annu. Rev. Ecol. Syst. 2002, 33, 475-505. [CrossRef]

34. Kraft, N.J.B.; Valencia, R.; Ackerly, D.D. Functional Traits and Niche-Based Tree Community Assembly in an Amazonian Forest. Science 2008, 322, 580-582. [CrossRef]

35. Swenson, N.G. The assembly of tropical tree communities-The advances and shortcomings of phylogenetic and functional trait analyses. Ecography 2013, 36, 264-276. [CrossRef]

36. Cadotte, M.; Albert, C.H.; Walker, S.C. The ecology of differences: Assessing community assembly with trait and evolutionary distances. Ecol. Lett. 2013, 16, 1234-1244. [CrossRef]

37. Thuiller, W.; Maiorano, L.; Mazel, F.; Guilhaumon, F.; Ficetola, G.F.; Lavergne, S.; Renaud, J.; Roquet, C.; Mouillot, D. Conserving the functional and phylogenetic trees of life of European tetrapods. Philos. Trans. R. Soc. B Biol. Sci. 2015, 370, 20140005. [CrossRef] [PubMed]

38. Losos, J.B. Phylogenetic niche conservatism, phylogenetic signal and the relationship between phylogenetic relatedness and ecological similarity among species. Ecol. Lett. 2008, 11, 995-1003. [CrossRef] [PubMed]

39. Burns, J.H.; Strauss, S.Y. More closely related species are more ecologically similar in an experimental test. Proc. Natl. Acad. Sci. USA 2011, 108, 5302-5307. [CrossRef] [PubMed] 
40. Devictor, V.; Mouillot, D.; Meynard, C.; Jiguet, F.; Thuiller, W.; Mouquet, N. Spatial mismatch and congruence between taxonomic, phylogenetic and functional diversity: The need for integrative conservation strategies in a changing world. Ecol. Lett. 2010, 13, 1030-1040. [CrossRef] [PubMed]

41. Safi, K.; Cianciaruso, M.V.; Loyola, R.D.; Brito, D.; Armour-Marshall, K.; Diniz-Filho, J.A.F. Understanding global patterns of mammalian functional and phylogenetic diversity. Philos. Trans. R. Soc. B Biol. Sci. 2011, 366, 2536-2544. [CrossRef]

42. Asefa, M.; Brown, C.; Cao, M.; Zhang, G.; Ci, X.; Sha, L.; Li, J.; Lin, L.; Yang, J. Contrasting effects of space and environment on functional and phylogenetic dissimilarity in a tropical forest. J. Plant Ecol. 2018, 12, 314-326. [CrossRef]

43. Carboni, M.; Acosta, A.T.R.; Ricotta, C. Are differences in functional diversity among plant communities on Mediterranean coastal dunes driven by their phylogenetic history? J. Veg. Sci. 2013, 24, 932-941. [CrossRef]

44. Wang, X.; Swenson, N.G.; Wiegand, T.; Wolf, A.; Howe, R.; Lin, F.; Ye, J.; Yuan, Z.; Shi, S.; Bai, X.; et al. Phylogenetic and functional diversity area relationships in two temperate forests. Ecography 2013, 36, 883-893. [CrossRef]

45. Xu, J.; Chen, Y.; Zhang, L.; Chai, Y.; Wang, M.; Guo, Y.; Li, T.; Yue, M. Using phylogeny and functional traits for assessing community assembly along environmental gradients: A deterministic process driven by elevation. Ecol. Evol. 2017, 7, 5056-5069. [CrossRef]

46. Luo, Y.; Cadotte, M.W.; Burgess, K.S.; Liu, J.; Tan, S.; Xu, K.; Li, D.; Gao, L. Forest community assembly is driven by different strata-dependent mechanisms along an elevational gradient. J. Biogeogr. 2019, 46, 2174-2187. [CrossRef]

47. Wu, R.; Cheng, X.; Zhou, W.; Han, H. Microbial regulation of soil carbon properties under nitrogen addition and plant inputs removal. PeerJ 2019, 7, e7343. [CrossRef]

48. Wu, R.; Cheng, X.; Han, H. The Effect of Forest Thinning on Soil Microbial Community Structure and Function. Forests 2019, 10, 352. [CrossRef]

49. Zanne, A.E.; Tank, D.C.; Cornwell, W.K.; Eastman, J.M.; Smith, S.A.; Fitzjohn, R.G.; McGlinn, D.J.; O’Meara, B.C.; Moles, A.T.; Reich, P.B.; et al. Three keys to the radiation of angiosperms into freezing environments. Nature 2014, 506, 89-92. [CrossRef]

50. Blomberg, S.P.; Garland, T., Jr.; Ives, A.R. Testing for Phylogenetic Signal in Comparative Data: Behavioral Traits Are More Labile. Evolution 2003, 57, 717-745. [CrossRef] [PubMed]

51. Webb, C.O. Exploring the Phylogenetic Structure of Ecological Communities: An Example for Rain Forest Trees. Am. Nat. 2000, 156, 145-155. [CrossRef]

52. Swenson, N.G.; Anglada-Cordero, P.; Barone, J.A. Deterministic tropical tree community turnover: Evidence from patterns of functional beta diversity along an elevational gradient. Proc. R. Soc. B Boil. Sci. 2011, 278, 877-884. [CrossRef]

53. Kembel, S.; Ackerly, D.; Blomberg, S.; Cowan, P.; Helmus, M.; Morlon, H.; Webb, C. Picante: R Tools for Integrating Phylogenies and Ecology. R Package Version 0.7.1. Bioinformatics 2010, 26, 1463-1464. [CrossRef] [PubMed]

54. Lichstein, J.W. Multiple regression on distance matrices: A multivariate spatial analysis tool. Plant Ecol. 2007, 188, 117-131. [CrossRef]

55. Zhang, J.L. Plantlist: Looking up the Status of Plant Scientific Names Based on The Plant List Database. R Package Version 0.5.3 2018. Available online: https:/ / github.com/helixcn/plantlist/ (accessed on 15 December 2019).

56. De Bello, F.; Šmilauer, P.; Diniz-Filho, J.A.F.; Carmona, C.P.; Lososová, Z.; Herben, T.; Götzenberger, L. Decoupling phylogenetic and functional diversity to reveal hidden signals in community assembly. Methods Ecol. Evol. 2017, 8, 1200-1211. [CrossRef]

57. Schall, P.; Schulze, E.-D.; Fischer, M.; Ayasse, M.; Ammer, C. Relations between forest management, stand structure and productivity across different types of Central European forests. Basic Appl. Ecol. 2018, 32, 39-52. [CrossRef]

58. Keren, S.; Svoboda, M.; Janda, P.; Nagel, T.A. Relationships between Structural Indices and Conventional Stand Attributes in an Old-Growth Forest in Southeast Europe. Forests 2020, 11, 4. [CrossRef]

59. Cadotte, M.W.; Carboni, M.; Si, X.; Tatsumi, S. Do traits and phylogeny support congruent community diversity patterns and assembly inferences? J. Ecol. 2019, 107, 2065-2077. [CrossRef]

60. Cavender-Bares, J.; Ackerly, D.D.; Baum, D.A.; Bazzaz, F.A. Phylogenetic Overdispersion in Floridian Oak Communities. Am. Nat. 2004, 163, 823-843. [CrossRef] [PubMed]

61. De Bello, F.; Thuiller, W.; Lepš, J.; Choler, P.; Clément, J.-C.; Macek, P.; Sebastià, M.-T.; Lavorel, S. Partitioning of functional diversity reveals the scale and extent of trait convergence and divergence. J. Veg. Sci. 2009, 20, 475-486. [CrossRef]

62. Swenson, N.G.; Stegen, J.C.; Davies, S.J.; Erickson, D.L.; Forero-Montaña, J.; Hurlbert, A.H.; Kress, W.J.; Thompson, J.; Uriarte, M.; Wright, S.J.; et al. Temporal turnover in the composition of tropical tree communities: Functional determinism and phylogenetic stochasticity. Ecology 2012, 93, 490-499. [CrossRef]

63. Mayfield, M.M.; Levine, J.M. Opposing effects of competitive exclusion on the phylogenetic structure of communities. Ecol. Lett. 2010, 13, 1085-1093. [CrossRef] [PubMed]

64. Yang, J.; Zhang, G.; Ci, X.; Swenson, N.G.; Cao, M.; Sha, L.; Li, J.; Baskin, C.C.; Slik, J.F.; Lin, L. Functional and phylogenetic assembly in a Chinese tropical tree community across size classes, spatial scales and habitats. Funct. Ecol. 2013, 28, 520-529. [CrossRef]

65. Kluge, J.; Kessler, M. Phylogenetic diversity, trait diversity and niches: Species assembly of ferns along a tropical elevational gradient. J. Biogeogr. 2011, 38, 394-405. [CrossRef]

66. Dainese, M.; Lepš, J.; de Bello, F. Different effects of elevation, habitat fragmentation and grazing management on the functional, phylogenetic and taxonomic structure of mountain grasslands. Perspect. Plant Ecol. Evol. Syst. 2015, 17, 44-53. [CrossRef] 
67. Chun, J.-H.; Lee, C.-B. Temporal Changes in Species, Phylogenetic, and Functional Diversity of Temperate Tree Communities: Insights from Assembly Patterns. Front. Plant Sci. 2019, 10, 294. [CrossRef] [PubMed]

68. Zhou, W.; Cheng, X.; Wu, R.; Han, H.; Kang, F.; Zhu, J.; Tian, P. Effect of intraspecific competition on biomass partitioning of Larix principis-rupprechtii. J. Plant Interact. 2017, 13, 1-8. [CrossRef]

69. Kraft, N.J.B.; Ackerly, D.D. Functional trait and phylogenetic tests of community assembly across spatial scales in an Amazonian forest. Ecol. Monogr. 2010, 80, 401-422. [CrossRef]

70. McGill, B.J.; Enquist, B.J.; Weiher, E.; Westoby, M. Rebuilding community ecology from functional traits. Trends Ecol. Evol. 2006, 21, 178-185. [CrossRef] [PubMed]

71. Kawai, T.; Tokeshi, M. Testing the facilitation-competition paradigm under the stress-gradient hypothesis: Decoupling multiple stress factors. Proc. R. Soc. B Boil. Sci. 2007, 274, 2503-2508. [CrossRef] [PubMed]

72. Uriarte, M.; Swenson, N.G.; Chazdon, R.L.; Comita, L.S.; Kress, W.J.; Erickson, D.; Forero-Montaña, J.; Zimmerman, J.K.; Thompson, J. Trait similarity, shared ancestry and the structure of neighbourhood interactions in a subtropical wet forest: Implications for community assembly. Ecol. Lett. 2010, 13, 1503-1514. [CrossRef] [PubMed]

73. Sundqvist, M.K.; Sanders, N.J.; Wardle, D.A. Community and Ecosystem Responses to Elevational Gradients: Processes, Mechanisms, and Insights for Global Change. Annu. Rev. Ecol. Evol. Syst. 2013, 44, 261-280. [CrossRef]

74. Liu, X.; Swenson, N.G.; Zhang, J.; Ma, K. The environment and space, not phylogeny, determine trait dispersion in a subtropical forest. Funct. Ecol. 2013, 27, 264-272. [CrossRef]

75. Silvertown, J.; Dodd, M.; Gowing, D.; Lawson, C.; McConway, K. Phylogeny and the Hierarchical Organization of Plant Divesity. Ecology 2006, 87, S39-S49. [CrossRef]

76. Eiserhardt, W.L.; Svenning, J.-C.; Baker, W.J.; Couvreur, T.L.P.; Balslev, H. Dispersal and niche evolution jointly shape the geographic turnover of phylogenetic clades across continents. Sci. Rep. 2013, 3, srep01164. [CrossRef] 